Anales de Literatura Hispanoamericana

ISSN-e: 1988-2351

\title{
Identidad deteriorada: Luces artificiales de Daniel Sada
}

\author{
María Esther Castillo
}

Resumen. Este escrito presenta una novela que parodia las estructuras simbólicas y culturales que modelan los cuerpos y la cotidianeidad de los sujetos. Luces artificiales, del escritor mexicano Daniel Sada, es un texto en donde se conjetura si la aceptación social del individuo depende del poder mercantil o del libre albedrío. Al considerar que la sociedad establece los medios para trazar categorías que repercuten en el mundo del arte, valoramos la pertinencia de un acercamiento sociosemiótico que permita enfatizar la trascendencia e interacción entre el discurso estético y las formas de vida. La novela de Sada es una ficción que nos hace reflexionar sobre la imagen del cuerpo, la construcción de la identidad y las relaciones de poder.

Palabras clave: Sada, identidad, deterioro, sociosemiótica, conjetura.

\section{[en] Spoiled identity: Artificial lights by Daniel Sada}

\begin{abstract}
This writing presents a novel which parodies the symbolic and cultural structures that shape the subject's bodies and everydayness. Artificial Lights, from the Mexican writer Daniel Sada, is a text where one conjectures whether the individual's social acceptance depends on the trade power, and not on free will. Considering that society establishes the means of tracing categories in the art world, we value the pertinence of a social-semiotics approach which allowes to emphasize on the body's image, the construction of identity and the relationships of power.
\end{abstract}

Keywords: Sada; identity; spoiled; social-semiotics; speculation.

Sumario: 1. Introducción. 2. El soporte sociosemiótico y retórico del discurso del poder. 3. La argucia de Luces artificiales²: el artificio de la identidad. 4. Conclusiones.

Cómo citar: Castillo, $\mathrm{M}^{\mathrm{a}}$.E. (2021) Identidad deteriorada: Luces artificiales de Daniel Sada, en Anales de Literatua Hispanoamericana 50, 237-246.

\section{Introducción}

Daniel Sada (1953-2011) ${ }^{3}$, en Luces artificiales, pone a prueba el discurso del poder simbólico que define la identidad y la cotidianeidad del individuo. A través de una fábula en donde la apariencia física se convierte en el signo que determina la aceptación social, el autor demuestra que la transformación de los cuerpos responde a la preferencia de un estereotipo.

Luces artificiales, desde el título, es una novela que argumenta el estado de una sociedad dominada por categorías mercantiles en donde los sujetos deben adoptar formas de vida que vulneran su libertad. En este tenor el autor formula las contradicciones del libre albedrío frente al entramado sociodiscursivo del poder y de las apariencias. A través de una narrativa que ensambla fundamentos éticos y estéticos, Sada presenta las dificultades a las que se ven obligados los seres humanos para ser aceptados.

La representación artística que logra el autor nos hace percibir el cuerpo como un ensamblaje de piezas que violenta su esencia y su identidad. Cuando el arte pondera la vulnerabilidad del cuerpo (real e

\footnotetext{
1 Consejo Nacional de Ciencia y Tecnología- SNI. México

E-mail: marescas2014@gmail.com

${ }^{2}$ Todas las citas de la novela provienen de la edición publicada en Joaquín Mortiz, 2002.

${ }^{3}$ Otras novelas del autor: Juguete de nadie (1985), Un rato (1984), Registro de cantantes (1999), El límite (1997), Lampa vida (1980), Albedrío (1989), Una de dos (1994); además de poemarios y ensayos críticos.
} 
imaginario) a través de un conjunto de figuras y discursos, también revela la trama simbólica que lo representa. En los tiempos actuales las expresiones simbólicas del cuerpo enfocan la identidad como un valor humano cada vez más mecanicista e ideologizado. El filósofo David Le Breton (2002), supone que el impacto identitario del cuerpo, en tanto objeto, se rige por diversos cambios de juicio o de percepción artística y social. En el específico arte literario, la vulnerabilidad, lo excepcional o la extrañeza del organismo y de las reacciones humanas, son características que se enuncian y se describen en todos los géneros, sean narrativos, poéticos o dramáticos; cada discurso y cada gesto producen contenidos y continentes simbólicos que a su vez generan una serie de respuestas, cuya trascendencia no sólo es artística sino también cultural y política.

En el continente del cuerpo humano, las expresiones mercantilistas que lo exhiben como un objeto más dentro de un mundo tan imaginario como real, demuestran que las circunstancias espaciotemporales en donde se genera la ideología y la ciencia, responden a una "pedagogía corporal", una suerte de configuración afectiva en la que se comienzan a privatizar o a recluir funciones como el placer, el deseo, la sexualidad y la limpieza corporal. Como señalara Norbert Elias:

por virtud de juicios morales y razones higiénicas, los individuos son modelados para convertir un comportamiento socialmente deseado en una auto coacción, esto es, en una disciplina corporal que aparece como un comportamiento deseado en la conciencia del individuo, como algo que tiene su origen en un impulso propio, en pro de su propia salud o de su dignidad humana. (Díaz Cruz, 2006: 153)

La literatura crea mundos en donde esos juicios y razones se interpretan y ponen en escena el vínculo intersubjetivo entre la vida y el cuerpo como expresión identitaria. Desde este contexto 'pedagógicocorporal", incluiremos la noción de "estigma" en la novela que nos convoca. El estigma es un criterio que se establece y analiza en las ciencias sociales y no en el arte; sin embargo, resulta una perspectiva interesante ya que coincide con los signos literarios relacionados con lo extraño o poco habitual, lo calificado como censurable o abominable de los cuerpos.

Según afirma el sociólogo Irving Goffman, el estigma es una clase de relación entre el atributo y el estereotipo:

el individuo estigmatizado, ¿supone que su calidad de diferente ya es conocida o resulta evidente en el acto, o que, por el contrario, ésta no es conocida por quienes lo rodean ni es inmediatamente perceptible para ellos? En el primer caso estamos frente a la situación del desacreditado, en el segundo frente a la del desacreditable. Ésta es una diferencia importante, aunque es probable que un individuo estigmatizado en particular haya experimentado ambas situaciones. (1993: 14)

A partir de este criterio al considerar que la sociedad establece los medios para trazar categorías y pedagogías de toda índole, y que éstas repercuten en el mundo del arte, es que valoramos el presente acercamiento sociosemiótico en Luces artificiales. Las nociones que de aquí deriven resaltarán la trascendencia e interacción entre el discurso estético y las formas de vida.

La literatura de Daniel Sada, además de sobresalir por inobjetables méritos estéticos, también destaca por exponer signos y situaciones ominosas de gran impacto social; la inclusión de mecanismos y condiciones de una existencia humana subrogada al ejercicio del poder define su obra. A través de la figura del alter ego, Sada revela y especula sobre la vulnerabilidad física y anímica de los sujetos ante la potestad de las instituciones familiares y públicas, en el contexto político y cultural del México contemporáneo. Al vincular la crítica y la ficción destaca la realidad caótica que nos rodea y que impresiona por su persistencia, por el abuso del poder y la descomposición social. Si bien Sada argumenta temas como la corrupción, el desmedido control de la prensa, las políticas erradas y la ineptitud de las autoridades en turno, es la presencia de los cuerpos vulnerados, despreciados, asesinados, desaparecidos y olvidados, lo que resalta en cada obra. Cada cuerpo parece convertirse en un signo que devela la identidad del propio país.

Importa aclarar que el autor configura este tipo de escenarios eludiendo la representación realista o naturalista, prefiere la retórica del estilo neobarroco como se refleja en la novela, Porque parece mentira, la verdad nunca se sabe (1999). Esta afamada obra expone el padecer de los sujetos ante los abusos del poder del Estado, al tiempo que imprime su poética neobarroca en el canon de la literatura mexicana. El acierto de su discurso, al conjugar el ornamento culterano, lo profuso del habla popular y un acre sentido del humor, provoca la reflexión acerca de la obra literaria, que siendo un símbolo estético, también reordena el mundo real de lo cotidiano (habla popular) generando nuevas perspectivas de valor humano. Citando al semiólogo Renato Prada, toda la narrativa de Sada sería una muestra de cómo "el símbolo estético, si bien construye 
su(s) valor(es) de sentido y significación tomando como forma la expresión de una lengua particular, la reformula al subordinarla a la intención estética, que nos lleva a referirnos en otros término, al mundo real de la vida cotidiana" (2003: 143).

\section{El soporte sociosemiótico y retórico del discurso del poder}

Luces artificiales puede leerse como una parodia, una sátira, una forma de provocación subversiva y moral. Quizás intente conmover el criterio de los lectores frente a la idea del poder, el querer y el deber. Para hacer ostensibles estas cuestiones, el autor pone a prueba una retórica persuasiva, así surge el ethos paródico ${ }^{4}$. La parodia, cuando marca el tono peyorativo de la sátira, posibilita la 'visibilidad' (discursiva y/o gestual) en la obra. Podremos visualizar la vulnerabilidad de Ramiro, el individuo protagónico, al comprender que la simulación de sus actos y la falta de credibilidad recae sobre sí mismo y no sobre los demás.

La tendencia de los discursos paródicos/satíricos, al basarse en la persuasión y al provocar diferentes grados de 'visibilidad', al modo de una sobreimpresión fotográfica, revela el matiz axiológico que funda o propicia modos específicos del actuar o del suponer, tanto del autor, como de los actores y lectores. La eficacia del sesgo paródico en Luces artificiales culmina en la producción de simulacros ${ }^{5}$. Los simulacros exhiben el contexto paradigmático del saber compartido de la sociedad a la cual pertenecen. Al hacer creer al sujeto que las formas del poder lo dominan, la simulación es la única fuente disponible para superar las 'pedagogías' impuestas.

El título mismo alude y pondera el simulacro del persuadir mercantil, al ofrecer una imagen del valor fiduciario en las jerarquías sociales. Al subrayar un marco de actuación en la apariencia física de los sujetos, Sada crea una figura 'estigmatizable' que confronte el descrédito a causa de lo 'imperfecto' de su fisonomía. La fealdad se presenta aquí no sólo como una apariencia desagradable sino como un estigma familiar y social que debe enmendarse. El narrador focaliza la desproporción específica del rostro como la prueba fehaciente de una mancha identitaria, una mácula que indica la imperfección e incluso la indignidad. Como antes mencionamos, cuando el cuerpo debe someterse a una disciplina moral e higiénica, o física, es para adecuarse a una forma de presencia y de vida socialmente autorizada.

La fealdad se articula y describe como el gesto indeleble que anima una serie de percepciones y de crisis. Con el fin de protagonizar una identidad que colisione contra los estatutos hegemónicos, morales y estéticos, el protagonista requiere de la transformación estética del rostro. Cuando Goffman propone la idea de estigma de acuerdo a la imaginería básica, creada por los "normales", la fealdad se inscribiría como una "abominación del cuerpo" (1993:14).

La supuesta 'abominación' demanda 'normalizar' la apariencia física. Más que incidir en una cuestión general sobre belleza versus fealdad, la abominación obedece a la idea de la ocultación o eliminación de un estigma, que, de manera extraordinaria, puede solventarse como un bien de consumo. En la percepción de los estratos y estructuras socioeconómicas establecidas en la novela, la noción de estigma se relaciona directamente con el poder económico. Una intervención estética, por ejemplo, cancelaría el estigma y zanjaría la cuestión que atribuye a la fealdad fallas de índole ético. Luego entonces, la franca mercantilización de la apariencia corporal, confronta y destaca la concepción de tal identidad 'desacreditable', que regula la situación del 'desacreditado'. El poder económico juega un papel trascendental en el valor que subyace y rige los procesos identitarios del sujeto. El estigma, agrega Goffman, responde al "rasgo general de la sociedad que se produce dondequiera que existan normas de identidad" (1993: 152). Esta tesis descubre una situación de comercialización con características que pueden o no imponerse sobre cualquier otro atributo cultural o ético.

Así pues, la alteración facial a la que será sometido el personaje Ramiro suscitará una serie de conjeturas acerca del citado estigma de la fealdad. Para conducir el debate de si la desproporción física es o no es una

${ }^{4}$ El ethos, en la parodia, se emparenta con el pathos, el sentimiento que el codificador busca comunicar al descodificador. "El ethos es una reacción buscada, una impresión subjetiva que es motivada, a pesar de todo, por un dato objetivo: el texto" (Hutcheon, 1992: 180). La parodia pone en cuestión la enunciación del sujeto al considerar la intención significante de la codificación en sí (Kerbat-Orechioni, 1992), al mismo tiempo, mantiene la intencionalidad pragmática para que el receptor decodifique el mensaje. En términos bakhtinianos la parodia se comprende como un fenómeno dialógico, "en el sentido en que se presenta una suerte de intercambio entre el autor y el lector o las competencias del mismo, así como su interpretación de una supuesta intención" (Hutcheon, 1992: 187).

${ }^{5}$ Landowski afirma que los simulacros garantizan, "mínimamente, una apariencia de adecuación entre los discursos y los universos de referencia que se ofrecen para su representación o descripción” (1993: 206). 
deshonra que precise un desagravio, el narrador incrementa la ironía, el absurdo y la comicidad en los niveles enunciativos y descriptivos. A través de una serie de intercambios discursivos sobre los valores éticos y económicos, la voz narrativa enfatiza las tramoyas del poder, caricaturiza las situaciones, y conjetura acerca de los criterios de una identidad sustentada en la economía.

Es muy interesante cómo Sada emplea la conjetura ${ }^{6}$ no sólo en Luces artificiales sino en toda su producción literaria, por ende, la conjetura se convierte en su estilo. Los personajes y los narradores dudan siempre acerca de su propia actuación, ninguno asevera ni posee la certeza del por qué de las acciones, de lo que dicen, piensan o son. A través de creencias, sospechas y deducciones, las voces narrativas confrontan ideas, comentarios y reacciones. Todos los relatos sadianos, al articular el texto como un objeto material de elucidación dentro y fuera del mismo, permite que las suposiciones y las creencias enunciadas demuestren que lo dicho es consecuente con el ejercicio estético y ético valorado dentro y fuera del texto.

En la series de inferencias y francos barruntos que verbaliza el narrador de Luces artificiales se reproduce igual número de supuestos; entre la broma y la seriedad, las inferencias descubren los recursos del poder entre el sujeto dominante y el dominado. En esta ocasión, la potestad dominante la representa el padre, él condiciona la transformación física del hijo. La autoridad paterna se establece mediante un contrato específico que el hijo debe cumplir para ser aceptado. En el estatuto de roles, Sada juega con la legitimidad de transacciones mercantiles y éticas, en aras de mostrar que las modalidades del poder ${ }^{7}$ rigen sobre las modalidades del querer de los personajes, anulando su voluntad y fincando la creencia de ser lo que no son.

El sentido del poder resulta de la norma que se acepta como ley regulatoria. El autor despoja al hijo de cualquier sustrato discursivo emocional-pasional, que permita manifestar alguna resistencia ante el dominio económico del padre, que naturalmente ejerce como parte normativa de la hegemonía social. Todas las reacciones que demanden del hijo una respuesta sensible, una reacción u oposición, se reducen a conjeturas y simulacros, actitudes y guiños que representan las fases de una pedagogía de subordinación y adiestramiento. Los simulacros no indican la aceptación identitaria del sí mismo, sino el deseo del otro, en los términos económicos del otro. Esta situación demuestra que si el sujeto requiere de una identidad, no basta con imaginarla o desearla, hay que representarla. El simulacro escénico conduce y adecua los actos y las reacciones de los personajes, al tiempo que, extratextualmente, nos posibilita a los lectores conjeturar acerca del deber hacer para poder ser.

En términos sosiosemióticos, el poder subraya las modalidades del deber y del querer hacer como parte de un mismo fenómeno, preexiste un poder que traspasa los cuerpos de los sujetos, obligados a lo que se suponga corriente, normal o cotidiano. Suponemos que la cotidianeidad, o las formas de vida que el sujeto adopta en su día a día, prefigura una serie de características con las que el sujeto humano, consciente o inconscientemente se identifica. El semiólogo Roberto Flores, en el texto, que precisamente se intitula Formas de vida (1999), elucida esta idea:

'Forma de vida' indica una morfología subyacente a la identidad de los sujetos, es decir, un entramado de signos de identidad que amueblan la vida cuya permanencia parece garantizar la misma identidad y cotidianeidad: la posibilidad de que, a lo largo de su existencia, el sujeto se reconozca a sí como sí mismo o de que sea reconocido por los otros. Es esta 'familiaridad con uno mismo' la que nos autoriza a examinar el lazo que une nuestros discursos con una forma de vida desde una perspectiva semiótica. (1999: 10)

La postura sociosemiótica sobre la aceptación de una cotidianeidad entre los individuos, emerge entonces como una perspectiva de carácter intersubjetivo que señala los lazos axiológicos en los límites de la intelección de los enunciados. En una expresión literaria que media entre la imagen del cuerpo, los signos del poder y las formas de actuar, está la gramática del texto organizada por la enunciación y lo enunciado; es decir, por las relaciones enunciativas entre los interlocutores comprometidos en la producción del discurso;

\footnotetext{
${ }^{6}$ La conjetura, en sí misma, contiene la interrogante semántico-pragmática de su codificación. Como afirma Prada, la conjetura “confronta el carácter radical e inmanente de los hechos del lenguaje como acto interpretativo" (2003: 150).

${ }^{7}$ En Historia de la sexualidad, Foucault afirma "Me parece que por poder hay que comprender, primero, la multiplicidad de las relaciones de fuerza inmanentes y propias del dominio en que se ejercen, y que son constitutivas de su organización; el juego que por medio de luchas y enfrentamientos incesantes las trasforma, las refuerza, las invierte; los apoyos que dichas relaciones de fuerza encuentran las unas en las otras, de modo que formen cadena o sistema, o, al contrario, los corrimientos, las contradicciones que aíslan a unas de otras; las estrategias, por último, que las tornan efectivas, y cuyo dibujo general o cristalización institucional toma forma en los aparatos estatales, en la formulación de la ley, en las hegemonías sociales". (1998: 112)
} 
esta operatividad enunciativa ${ }^{8}$ define la propuesta sociosemiótica. Las formas de vida, al ser lo que rige la congruencia de los usos y de los juegos de lenguaje, subyace en el ámbito representacional de un texto de ficción.

Creemos que el discurso literario reproduce un paralelismo equivalente al de la comunicación social. Como sugiere Landowski, el discurso literario hace sentido al revelar la construcción del sujeto a través del lenguaje. Es por medio de los juegos del lenguaje que describimos acciones y enunciamos proposiciones que nos remiten a una definición, a una explicación y/o al enfrentamiento del espacio social de donde surgen. Mientras las ciencias sociales le asignan al cuerpo y a la apariencia una posición determinada dentro del simbolismo general de la sociedad, los lenguajes artísticos exploran innumerables formas de comprender tal simbolización. Al fundamentar la figuralidad del cuerpo como objeto semiótico en el texto literario, consideramos la ventaja del concierto interdisciplinario entre lo social y lo artístico.

La realidad simbólica del cuerpo, en consecuencia, yace como expresión del pensamiento que comunica tanto su presencia como su invención. Así sostiene Catrina Imboden que "la comunicación humana está basada en la corporeidad del discurso y, viceversa, el cuerpo, al inscribirse en un sistema significante, deviene cuerpo figurado, esto es, una construcción discursiva" (2006: 7)9.

\section{La argucia de Luces $^{\text {artificiales }}{ }^{10}$ : el artificio de la identidad}

Plática de hombre a hombre, o plática de autoridad relumbrosa con un subordinado flaco y pusilánime, o inclusive un monólogo con final feliz: Primero que nada, hijo, debo pedirte una disculpa. Desde hace muchos años he querido hablar contigo acerca de tu fealdad...este...lo que tanto te ha hecho sufrir, sobre todo, porque has tenido la referencia constante de tus hermanos, que son bellos y se casaron con mujeres bellas y tienen hijos bellos. Tus hermanos son triunfadores. Pero tú no. Tú nunca vas a pasar de ser un cajerito de banco y eso, pues...este...me duele. De hecho, como te podrás dar cuenta, yo también soy feo, pero a sabiendas de mi problema [...] procuré hacerme capitalista (...) inclusive haciendo trampas con quien se dejara. Así que el dinero me hizo atractivo y fue ésa la razón por la que pude conseguir una muñeca tan hermosa como tu madre. Ahora bien: a mi Dios me dio la facultad de engatusar a la gente con provecho, pero a ti, para colmo, no te dio ni siquiera dos gramos de mi talento y esa carencia, aunada a tu fealdad, te hace demasiado indefenso Sé que podrías preguntarme ipor qué indefenso...? Bueno, déjame explicarte: siempre he pensado que entre más poblado esté el mundo más en desventaja estarán los feos. A ellos [...] no les queda más remedio que ser inteligentes, e incluso tramposos [...] o poderosos, a fin de aplastar al prójimo cuantas veces se pueda. Todo eso soy yo, pero tú hijo, eres demasiado bueno y obediente. Sólo tienes facultades para sobrellevar las cosas...así...me-ra-men-te...” (51) ${ }^{11}$

Sada expone la imagen desvalorizada del hijo ante la autoridad del padre como un objeto de carácter mercantil. Corroboramos en el párrafo citado, que el narrador pone en escena el discurso persuasivo del hacer creer, con el fin de que el narratario se sitúe en el plano de los prejuicios culturales que servirán para reflexionar sobre su propia identidad. Sea como sea, el decir de la autoridad paterna, así sea conseja, embuste, ficción o mito, hace sentido en la escucha del hijo, sobre todo porque el 'buen argumento' para convencerlo acerca de la 'corrección del deterioro', tendría un beneficio secundario: «Y sí, a ti te daré el setenta por cierto de mi herencia [...] A tus hermanos no les daré ni un centavo, puesto que con su belleza han conseguido más de lo que merecen, aunque no son que digamos unas luminarias» $(52)^{12}$.

El autor se propone, con mucho ingenio, desentrañar la factibilidad identitaria que brinda el poder mediante un contrato fiduciario que establece la obligación entre las partes: el padre manda y otorga, el hijo acata y recibe. Las reacciones patéticas, grotescas y tragicómicas, que el hijo simula tratando de cumplir el contrato paterno, autentificarán los zarandeos de una biografía autorizada e impuesta por el padre.

El discurso intensifica la fealdad como estigma acentuando epítetos descalificadores: "un hombre feo", un "monstruo", cuyo rostro exhibe "nariz de hueso de mango", "ojos saltones", "labios de intestino grueso" y "horrendas

\footnotetext{
${ }^{8}$ En la perspectiva semiótica que adoptamos como sistema de significación, se entiende el proceso de enunciación como "la apropiación del lenguaje por parte de un yo que apela a un tú, porque pone en juego los diversos aspectos de la subjetividad configurada por el propio discurso. La constitución misma del sujeto de enunciación [...] nos hace comprender la conformación discursiva de la subjetividad” (María Isabel Filinich, Enunciación, 2005: 9).

${ }^{9}$ Landowski opina que "la importancia de la concepción sociosemiótica del cuerpo reconoce tanto las bases lingüísticas, como el carácter operatorio que sirve para una mejor comprensión de la dimensión social y estética de los hechos de la significación" (1993: 221).

${ }^{10}$ Todas las citas de la novela provienen de la edición publicada en Joaquín Mortiz, 2002.

${ }^{11}$ Cursivas en el texto.

${ }^{12}$ Cursivas en el texto.
} 
cejas". La descalificación física, aunada al 'poco talento', sustenta la absoluta extravagancia de la fábula que se acredita desde el párrafo que inicia con la 'plática de hombre a hombre'. Entre las condiciones del contrato, la primera es que se someta a la cirugía plástica para corregir su 'horrendo rostro'; el otro requisito es que se asile en la ciudad capital, que nunca regrese ni al pueblo ni a la familia. Pero, en caso contrario ¿Si por cualquier motivo, Ramiro no cumple el contrato, éste podría invalidarse? Como Goffman sugiere, "es probable que el individuo estigmatizado utilice su estigma para obtener 'beneficios secundarios', como una excusa por la falta de éxito que padece a causa de otras razones" (1993: 21).

Podemos apreciar que los discursos, acciones y reflexiones, sobre el significado del poder económico sustentado en el contrato, si bien produce beneficios, ponen en duda la posibilidad del mismo a través de toda clase de conjeturas elaboradas metadiscursivamente ${ }^{13}$. Así escuchamos la perorata del hijo cuando se marcha del terruño a la capital con el fin de someterse a una cirugía plástica:

[Ramiro quería] Colgar el pasado. La infinita tristeza de la fealdad que se va volando muy mal [...] La fealdad remontaba ya el vuelo. Podía desplomarse un poco más allá y iqué bueno! Tragos de arrepentimiento: chiquiteo pensativo. Aunque...De lo único que se arrepintió Ramiro fue de haberse cambiado de hotel. No venía al caso pagar lujos tan a guilla. El acuerdo con el cirujano pudo establecerse desde allá y en seguida realizar el cambio, pero a un hotel más modesto [...] ominoso apuro, pues, en volandas planear el aterrizaje: cierto que enfadoso: justo el día de mañana para el cambio operoso: ergo: no más derroche. Entonces: a la espera lo modesto: un hotel furris pero mono, útil para guardar las maletas por cuánto tiempo, puesto que Ramiro estaría en rehabilitación en un cuartito de hospital durante... ¡sepa! Por lo pronto Ramiro se vio en el espejo como si se despidiera de todo lo que fue su vergüenza de raíz y a su vez, harto ocioso, quiso figurarse los cientos de caras hipotéticas que podría tener ya casi, de las cuales una, ¡sólo una! (artificial, guapa, interesante): con la que, entre otras cosas, iría envejeciendo, pero también...

Ramiro emprende el viaje del excluido con la promesa del beneficio económico y el sentimiento de una identidad anónima. Tampoco pretende una saga heroica al dejar una forma de vida que carecía de autenticidad. Así pues, Ramiro se instala en la ciudad de México para someterse a la impuesta cirugía estética. Sin alguna experiencia fuera de su hogar, alquila un "dizque penthouse". Por azares del destino tal departamento colinda con el de unos individuos, que, según escucha al otro lado de la delgada pared, planean asaltar un banco. Esta fábula secundaria acerca del latrocinio parece fortuita; sin embargo, es indispensable para complicar la trama, para desautorizar el contrato fiduciario y darle la vuelta a la maniobra urdida por el padre. El narrador afirma que el robo al banco no sólo fue anunciado, sino también perpetrado. Esta fábula secundaria tergiversa la odisea al sustentar la causa por la cual Ramiro debe regresar al pueblo incumpliendo el contrato. No obstante, con el nuevo rostro, queda en el aire la cuestión acerca de la identidad del sujeto que regresa.

Mientras Ramiro se instala en su 'dizque penthouse' e indaga todo lo relacionado con los beneficios y riesgos de la medicina estética, trascurren dos meses y medio de consultas con un tal doctor Avendaño. Él le explica, "punto por punto", las causas y los efectos de una cirugía facial. El narrador sadiano describe con minuciosidad los procedimientos quirúrgicos y los riesgos posibles que el paciente podría experimentar; la enunciación y descripción de cada término reproduce el culteranismo del autor, enriquecido con las referencias taxonómicas pertinentes. Así se acredita el narrador cuando cuenta que Ramiro decide comprar un libro (recomendado por el doctor Avendaño cuando éste se cansa de explicarle los procedimientos), para enterarse acerca de los términos y tecnicismos que intervienen para operar cada órgano facial:

Nómbrese la frente, las mejillas, el mentón, las cejas, y agréguese en franco desorden una infinitud de tecnicismos a flor de flor a bien de una inducción inevitable hasta la raíz. Raíces por mor de un subsuelo hondo [...] nomás porque sí, va una retahíla al azar: colgajo mucoperióstico triangular; panículo adiposo; paredes hipofaríngeas; lobectomía total; carcinoma; aspiración en el mediastino [...] Consultas pagadas con aumentos considerables: cada vez más: mucho más delirio y conveniencia. Así que otra retahíla [...] solución de Zenker a la fosa vacía; glándula parótida; alambre de Kirschner [...] ¡Ea!, y es que de cada noción se desprendían minucias como estrellas en el cosmos. (121-122)

\footnotetext{
${ }^{13}$ El metadiscurso es una forma evaluativa de discurso. "Se relaciona con el nivel de la personalidad, o tenor, del discurso e influye en cuestiones tales como la cercanía o distancia del autor, la expresión de la actitud, el compromiso con lo aseverado y el grado de participación del lector". Hyland en Müller, Gisela. Metadiscurso y perspectiva: Funciones metadiscursivas de los modificadores de modalidad introducidos por 'como' en el discurso científico. Signos, Valparaíso, vol. 40, nº .64, 2007, pág. 357).
} 
La cirugía que transformaría a Ramiro en otro: "ultracorregido [...] la diferencia guapa, en efecto: germen de vanidad en ese exterior artificial y en su alma indemne aún ennegrecida" (193), contradecía incluso la ideología del propio doctor Avendaño. Para desaliento del paciente, el cirujano reiteraba: "Si Dios te hizo feo, la cirugía estética no es otra cosa que una manera sofisticada de retar a Dios [...] a Ramiro le quedaba claro que corregirse la cara era ir contra los designios del todopoderoso, pero...ì qué?" (123). Consideremos, al calce de la situación, que el propio hecho de someter a cirugía el rostro, afecta la parte del cuerpo que más encuadra el atributo identitario. La indeterminación enunciativa que maneja Sada, entre el escrúpulo y la llaneza (‘¿y qué?’), recae sobre la confianza y desconfianza, no ya del procedimiento quirúrgico ni de los resultados esperados, sino sobre el significado de la identidad. La imprecisión o la ambigüedad, son elementos importantes para enfatizar las actitudes vacilantes de los involucrados; el cirujano y el paciente dependen del poder mercantil pues de cualquier forma lo que importa es no contravenir los dictados de una autoridad que supera a ambos.

Sea como sigue la trama, la vida del nuevo 'galán' pone a prueba la consigna del padre sobre la pertinencia del cambio. El franco chantaje en pos de la guapura, y por extensión de la masculinidad, convierten a Ramiro en el objeto experimental que ratifica su idea: "en fin, belleza es sufrimiento" (175).

La intervención estética que da brillo a las 'luces artificiales', responde al núcleo conceptual que Landowski clasifica como el "modo económico" (1993: 7) que se distancia de los escritos de psicología social, al tiempo que permite dimensionar simbólicamente al cuerpo como un mero instrumento mercantil, alejado de premisas pasionales o emocionales. Este alejamiento Sada lo traduce y representa con remedos, parodias y simulacros.

Cuando el protagonista especula sobre las retribuciones colaterales que la cirugía plástica le otorgaría, la primera es la iniciación sexual. Días previos a la operación estética, Ramiro acude a un tugurio en donde concibe la imagen de "su mujer maravilla" en la figura de una vedette que lo rechaza al mirarlo, sin importar el pago que recibiría a cambio. Ante este nuevo rechazo, y dado que no podía ni con dinero, conquistar a 'la mujer maravilla', espera obtener mejores resultados después de la cirugía. Semanas después, ya con su 'estrenada guapura', no prueba fortuna con la vedette, mejor "se conforma con Delia", una mesera que trabajaba en una fonda cercana a su departamento, en donde él era cliente asiduo. La intervención de este personaje femenino es crucial; Delia es quien le lanza el primer piropo certificando el éxito de la 'guapura', suple a la ansiada 'mujer maravilla' y lo inicia en la "mecánica del sexo". Sin embargo, Delia es también la persona que lo extorsiona y despoja de buena parte de la herencia cuando el fingido romance concluye y se desenmascara el interés económico que lo sustentaba. Ramiro creía gozar de una nueva vida en compañía de Delia, confiaba tanto en ella que decide entregarle gran parte de su fortuna por dos razones incomparables. Primero porque debía demostrarle 'el amor verdadero' a esta mujer necesitada (con una madre paralítica y un hijo con síndrome Down). Y segundo porque ella representa no el amor sino la amenaza. El caso es que confunden a Ramiro con el ladrón del banco y ella es quien puede identificarlo y entregarlo a las autoridades. Delia es el personaje que pone a prueba los avatares y paradojas del poder económico.

La saga del héroe se trunca y concluye con la huida al terruño: "Desobedeciendo a su padre muerto, quien por cierto, ¿qué diría de todo esto? Desde la tierra Ramiro podría responderle: Ya ves, papá, mi vida no puede cambiar tanto...Al contrario, ahora está empeorando...El orden metafísico aplastante" (267). La "guapura" de Ramiro debe ocultarse para subsistir en una sociedad que vuelve a rechazarlo al identificar su rostro con el de un ladrón. Cuando regresa al pueblo, resume para sí todo el experimento en una frase: "los lastres de malogro orondo" (331). Con "los millones que le quedan" decide comprar la papelería de su pueblo, ahí conoce a Zoila, "una clienta regular", que si bien tampoco representaba a su 'mujer maravilla', sí podía con ella "formar una familia", "tener hijos, uno al menos", sin importar la heredable fealdad, "lo amaría tal como era y a quien ni por error lo obligaría a cambiar de cara. Ningún artificio ¡nunca!, de eso estaba seguro" (331).

La estructura y ritmo narrativos, basados en la intercalación de incesantes conjeturas, facilita la intromisión del narrador para explicar, parodiar e ironizar, el actuar y el decir del personaje tragicómico. Ramiro rubrica múltiples composiciones metanarrativas saturadas de cláusulas enunciativas y descriptivas (supuestos, explicaciones, correcciones, alegatos, añadidos, perífrasis), que por sí mismas exteriorizan la trascendencia de un metalenguaje sustentado en hipótesis. Estos procedimientos discursivos convienen, además, porque enfatizan la relación entre el poder y el deber hacer, ante la noción de una identidad maleable, cuyo ser y actuar no responden a sus deseos sino a un contrato mercantil de oferta y demanda. La parodia y la conjetura son recursos que otorgan realidad a la modalidad de lo viviente; así se aprovecha y justifica la inserción del lenguaje biomédico que atañe a la cirugía plástica, a sus procesos, resultados y peligros, y que funcionan como engranajes para atraer la gestualidad descrita en cada ocasión: pantomimas, posturas, alharacas, etcétera. 
Los lenguajes especializados, los mecanismos referenciales y metanarrativos, apoyan el trasunto literario que deviene metaficción. Declaraciones discursivas como: "Hemos llegado de rebote a lo que habíamos prometido en otro capítulo" (126); "Antes que nada es pertinente aclarar" (145); "Páginas tras páginas de inopia: una abaniqueo" (162), "El vaciado argumental de Ramiro fue caótico porque para él era cargante narrar de principio a fin (189), "Tanto pormenor ¡episodio tras episodio como si estuviese escalando una montaña o descendiendo a un infierno? (189), son ejemplos de una fraseología que circula y repercute como si se interpretara la conciencia ficcional e identitaria del personaje-narrador, obligado a confeccionarse disfraces y a simular una forma de vida en la realidad en turno.

En la configuración de otras identidades, Ramiro vislumbra que la vida tomaría su propio derrotero y decidirá su proceder: "Una historia que nacía falsa y continuaría más falsa, trompicada, y acabaría ¿cómo...? Demostrativa y lerda ¿sólo para moldear la fealdad? Molde frágil, aunque...Pues bien, de ahora en adelante Ramiro Cinco se llamaría como se oyó: Nombre de alcurnia, harto heráldico" (76).

Al traspasar el umbral de una vida y alucinar otra, Ramiro debe configurar su propia ficción, así se obliga a pensar y a representar situaciones que en consecuencia desencadenan otra serie de realidades. En la dinámica de las conjeturas acerca de la vida y del actuar, el protagonista debe despedirse física y anímicamente de quien fue para jugar el juego del otro.

Nos encontramos ante una variación de la forma de parodia satírica que pragmáticamente subraya el trayecto discursivo/enunciativo de los sujetos, y cuya afectación los confronta consigo mismos y ante una audiencia atenta a las marcas enunciativas del poder. El foco de percepción sobre 'Aquella horripilancia que tantos problemas le trajo', si bien rige la existencia del sujeto afectado, también focaliza las acciones subsiguientes que deben realizarse según el contrato instituido: 'Todo perfilado hacia un cinismo estupendo y hacia una vanidad maravillosa'. El protagonista, en el rol del sujeto social, acepta su transformación a cambio del goce prometido, instigado por la modulación de aspecto incoativo del discurso (en los adverbios: estupendo, maravilloso, etc.), que desde ya previene ciertos reparos: 'Pero de eso después se hablará'. Reconvenciones como ésta, orientan la vacilante historia del sujeto padeciente y estigmatizado hacia la quimera fabricada por otro sujeto cuyas intenciones también se frustran.

Observemos los signos de una 'identidad deteriorada' que extienden el contexto cultural de una sociedad marginada dentro de sus propios límites, primero ante la institución familiar como única audiencia, y después, con la estrenada 'guapura', contra otra audiencia de orden público e incluso jurídico. Entre la precariedad y la espectacularidad del trayecto identitario, se desacredita la credibilidad propia del sujeto en esa carrera moral simbolizada por estigma. La falla de origen, al basarse en la comprensión de la diferencia entre un "nosotros" aceptado y establecido en la comunidad, frente a otro que no pertenece a los "normales", puede adecuarse a la lógica del poder mercantil del grupo dominante. Sada ensaya esta idea del 'yo' y el 'nosotros' como un ensamble tragicómico a partir de experiencias verosímiles e imaginativas, que permiten valorar el origen de las prácticas sociales, cuando lo trágico y lo patético se percibe con una mirada cáustica. Series de tentativas ilusas frustran al sujeto porque le son ajenas y, porque, al final, en la confusión de qué es la identidad, nuevas relaciones cambian las normas y las expectativas. La carrera moral de los actores sadianos no puede asentarse en el sentido del individuo sino en el de la comunidad que siempre lo expulsa de un 'nosotros'. Los personajes reciben y aceptan contratos basados en suposiciones falsas sobre un ego rechazado, que debe ser adaptado o 'corregido' por los demás.

La información social que la audiencia devuelve a la actuación conlleva signos equívocos, digamos que la simbolización del mundo no sólo tiene un rostro social, sino uno fidedigno y otro simulado. El entorno público concibe el simulacro que se asume como si estuviese sólo en la esfera del otro, sin reconocer que el sujeto (yo) y su entorno (nosotros) también sufren alteraciones. La 'corrección' de la fealdad, en este caso, implica desde ya un develamiento del simulacro social que rige la realidad, y que, al denunciarse, difunde explícitamente la actitud crítica del escritor al relatar la percepción sistemática de los valores humanos como una invención existencial acomodadiza.

La enunciación del léxico implementado en Luces artificiales (estético, médico, cultural), mantiene el preciso matiz político sobre el contexto simbólico de los sujetos. Para el autor existe la dominación, la hostilidad, la dependencia y la representación, como los ejes que manipulan las relaciones simbólicas de los cuerpos. Como Goffman sugiere, la información social siempre es transmitida a través de símbolos: "Cualquier símbolo particular puede confirmarnos simplemente lo que otros dicen del individuo, completando la imagen que tenemos de él de manera redundante y segura" (58). El 'estatuto' y/o el 'prestigio' son 'desidentificadores' cuando no responden a lo supuesto. Este supuesto nos indica que tanto los signos sociales como los símbolos estéticos definen al grupo, a la audiencia que los percibe, y que, en consecuencia, no son permanentes. En el fenómeno literario que nos concierne es innegable que los 
calificados estigmas pueden ser empleados a voluntad en un texto artístico; el artista no los descarta, al contrario, los refuerza en el sentido performático del simulacro inherente a todo el arte.

\section{Conclusiones}

La ficción literaria, al presentar su propia estructura narrativa y simbólica, apoyada en los planos de expresión y contenido que se constituyen como el plano de la referencia, descubre la organización profunda de su sentido. Al subrayar los fundamentos intersemióticos de toda producción de sentido es posible integrar puntos de reencuentro a partir de las propias funciones ilocutorias del lenguaje. Tanto los interlocutores reales como los ficticios están dotados de competencias modales (querer, deber, saber, poder), y de roles o papeles actanciales que son asumidos en la sociedad y recreados u originados fictivamente en la narración literaria. El saber de quienes manejan a un tiempo el discurso social y el discurso poético, recupera principios filosóficos, psicológicos e institucionales, que pasan por el tamiz de las teorías del lenguaje literario y de los actos de habla. La perspectiva sociosemiótica permite considerar tanto el contexto de las situaciones reales, como de las fictivas; de aquí la pertinencia de leer la novela de Daniel Sada como una forma emblemática del hacer pragmático en la ficción. Salvado el punto de que todo escritor manipula los mecanismos de la comunicación, creemos que el acto estético responde al intercambio social de ideas y de objetos, pero también promueve actitudes, con ellas se negocia, confronta y reformula, acuerdos de orden cognitivo y pasional. Los actores ficticios materializan los actos de manipulación discursiva. Como sugiere Landowski, no se trata de que el sujeto operador transforme al mundo "sino de mostrar el hacer manipulatorio de un metasujeto destinador que ejerce su capacidad de hacer actuar a sus semejantes y seguramente, si se da el caso, de hacerse actuar a sí mismo" (201).

El simulacro (la performance), que en la ficción significa poner en escena la palabra, o visualizar el "como si" del relato, Sada lo magnifica o refracta mediante los actos de habla, deudores del intercambio social, cultural y económico, o contractual. En Luces artificiales el poder representado por dichos intercambios postula el carácter intersubjetivo de un lazo de "confianza", asimismo, reordena las reacciones de incertidumbre sobre lo que podría suceder con una transformación física. El cambio identitario al que el padre obliga sobredetermina el fracaso de la aventura. El espejo no le ofrece al hijo la imagen deseada de un sí mismo íntimo sino la imagen que publica la impostura, y aún el encarecimiento de la transacción, cuando la odisea cambia su rumbo. La prescripción del padre atraviesa el estatuto semiótico de la 'verdad' de manera inesperada porque el código de honor filial se ve mancillado por el poder de la apariencia.

Podemos reiterar, finalmente, que en la narrativa de Sada existen ideas de omnipotencia fallida, de juicio temerario, de reticencia y mordacidad, que obligan a los personajes a actuar doblemente encubiertos. Todos los actores, como los seres humanos, juegan a transformarse en otros, todos poseen un marca quijotesca que no desconocen, que utilizan. En este caso, la cirugía plástica es la cirugía del procedimiento identitario en sí. El espejo refracta al individuo, pero adulterado, le devuelve la imagen de quien forma parte de la intriga de otro.

Para sostener la farsa del artificio la intriga sustenta la autoridad mercantil que puede reemplazar el sujeto en objeto. Sada parece afirmar que si alguien tiene el poder del que el otro carece, la transfiguración de la imagen comprueba que la realidad identitaria es sólo una mascarada.

\section{Referencias bibliográficas}

Díaz, Cruz (2006), “La huella del cuerpo. Tecnociencia, máquinas y el cuerpo fragmentado”, en El cuerpo figurado Tópicos del seminario 16-. Puebla: BUAP.

Filinich, María Isabel (2005). Enunciación -enciclopedia semiológica-. Buenos Aires: EUDEBA

Flores, Roberto. Formas de vida -Tópicos del seminario 1-. Puebla: BUAP.

Foucault, Michel (1998). Historia de la sexualidad 1. Ciudad de México/Madrid: Siglo XXI.

Goffman, Irving (1993). Estigma. La identidad deteriorada. Buenos Aires: Amorrortu Editore.

González, Sawczuk et.al. (2018). Literatura y memoria: espacios de subjetividad. https://dx.doi.org/10.4067/S0716-58112014000100004

Imboden, Catrina Rita (2006), "Presentación”, en El cuerpo figurado-Tópicos del seminario 16-. Puebla: BUAP.

Hutcheon, Linda (1992), "Ironía, sátira y parodia”, en De la ironía a lo grotesco. Cd. de México: UAM.

Kerbrat O., Catherine (1992), "La ironía como tropo”, en De la ironía a lo grotesco. Cd. de México: UAM.

Landowski, Eric (1993). La sociedad figurada -ensayos de sociosemiótica-. Puebla: BUAP.

Le Breton, David (2002). Antropología del cuerpo y modernidad. Buenos Aires: Nueva Visión.

----------, ------ (2007). Adiós al cuerpo. Ciudad de México: La cifra editorial. 
Müller, Gisela (2007), "Metadiscurso y perspectiva: funciones metadiscursivas de los modificadores de modalidad", Signos, Valparaíso, vol. 40, nº 64, pág. 357.

Prada, Renato (2003). Hermenéutica, símbolo y conjetura. Torreón/Puebla: Lupus Inquisidor.

Sada, Daniel (2002). Luces artificiales. México: Joaquín Mortiz.

Yelin, Julieta (2016), "Biopolíticas de la interpretación”, Revista Estaçao Literária, Londrina, vol. 17, págs. 28-39. 